\title{
Changes in cardiorespiratory fitness, psychological wellbeing, quality of life, and vocational status following a 12 month cardiac exercise rehabilitation programme
}

\author{
L D Dugmore, R J Tipson, M H Phillips, E J Flint, N H Stentiford, M F Bone, \\ W A Littler
}

\begin{abstract}
Objective-To examine and evaluate improvements in cardiorespiratory fitness, psychological wellbeing, quality of life, and vocational status in postmyocardial infarction patients during and after a comprehensive 12 month exercise rehabilitation programme.

Subjects-The sample population comprised 124 patients with a clinical diagnosis of myocardial infarction (122 men and two women).

Interventions - 62 patients were randomly allocated to a regular weekly aerobic training programme, three times a week for 12 months, and compared with 62 matched controls who did not receive any formal exercise training. A five year follow up questionnaire/interview was subsequently conducted on this population to determine selected vocational/lifestyle changes.
\end{abstract}

Action Heart, Cardiac Rehabilitation Centre, Wellesley House, 117 Wellington Road, Dudley, West Midlands DY1 1UB, UK

L D Dugmore

R J Tipson

M H Phillips

Cardiology

Department, Dudley

Group of Hospitals

NHS Trust, Dudley,

West Midlands, UK

E J Flint

N H Stentiford

Department of Medicine, South Tyneside District

Hospital, South

Shields, Tyne and

Wear, UK

M F Bone

Cardiology

Department,

University Hospital,

Edgbaston,

Birmingham, UK

W A Littler

Correspondence to: $\mathrm{Dr}$ Dugmore.

Accepted for publication 10 November 1998
Results-Significant improvements in cardiorespiratory fitness $(p<0.01-0.001)$, psychological profiles $(p<0.05-0.001)$, and quality of life scores $(p<0.001)$ were recorded in the treatment population when compared with their matched controls. Although there were no significant differences in mortality, a larger percentage of the regular exercisers resumed full time employment and they returned to work earlier than the controls. Controls took lighter jobs, lost more time from work, and suffered more non-fatal reinfarctions $(p<0.05-0.01)$.

Conclusions-Regularly supervised and prolonged aerobic exercise training improves cardiorespiratory fitness, psychological status, and quality of life. The trained population also had a reduction in morbidity following myocardial infarction, and significant improvement in vocational status over a five year follow up period.

(Heart 1999;81:359-366)

Keywords: myocardial infarction; exercise training; fitness; quality of life

There are conflicting opinions in the United Kingdom over the value and benefit of cardiac rehabilitation. Some protagonists firmly believe that it has a positive effect on the recovery process following myocardial infarction. ${ }^{1-3}$ Others have questioned this and have claimed that while exercise training in particular increases confidence during the early stages of convalescence after myocardial infarction, in the long term it has little effect on cardiac function, everyday life, and emotional state. ${ }^{4}$ Analysis of the effects of cardiac rehabilitation has sometimes been hampered by the heterogeneity of patients studied. This has led to suggestions that formal exercise programmes are probably not justified for all patients. $^{5}$

Cardiac rehabilitation - and specifically exercise training in patients after myocardial infarction-may require labour intensive efforts to be effective. In order to justify its wider use with such populations, its physiological, psychosocial, and vocational benefits need to be critically examined. There have been no randomised controlled studies on these outcomes in the United Kingdom, although it has been suggested that cardiac rehabilitation is an efficient use of health care resources. ${ }^{6}$

Our aims in this study were to examine the differences between postmyocardial infarction patients receiving comprehensive exercise rehabilitation and matched controls receiving no formal rehabilitation. The results of this investigation may be viewed in the light of British Cardiac Society working party reports on cardiac rehabilitation, which recommend that every major district hospital that treats patients with heart disease should provide a cardiac rehabilitation service. ${ }^{6} 7$

\section{Methods}

Patients recruited for this study were drawn from the clinical workload of the consultant physicians at Russells Hall Hospital, Dudley, West Midlands, UK. The research population included 124 patients (122 male and two female) who had all suffered clinically documented myocardial infarction between 1984 and 1988. The conventional WHO cardiac enzyme and ECG criteria of myocardial infarction were used. The population was subdivided into groups with good and bad prognosis, based on criteria set out below (see "Study design and procedures")

Good prognosis group-There were 36 patients with a good prognosis and their matched controls. Of these, 19 pairs had had an anterior infarct and 17 pairs an inferior infarct. 
Table 1 Age, height, weight, body mass index (BMI), and percentage of body fat scores of the good and poor prognosis groups and their matched controls

\begin{tabular}{llllll}
\hline & \multicolumn{2}{l}{$\begin{array}{l}\text { Good prognosis population } \\
(n=72 ; 70 \text { male, 2 female })\end{array}$} & & \multicolumn{2}{l}{$\begin{array}{l}\text { Poor prognosis population } \\
(n=52 ; \text { all male })\end{array}$} \\
\cline { 2 - 3 } \cline { 5 - 6 } & Treatment group & Control group & & Treatment group & Control group \\
\hline Age (years) & $51.6(1.28)$ & $52.9(1.35)$ & & $59.3(1.4)$ & $59.5(1.36)$ \\
Height $(\mathrm{cm})$ & $170.3(1.13)$ & $170.7(0.90)$ & & $171.0(1.37)$ & $169.4(1.20)$ \\
Weight $(\mathrm{kg})$ & $76.3(1.78)$ & $78.9(1.76)$ & & $76.1(2.27)$ & $74.3(2.66)$ \\
BMI $\left(\mathrm{kg} / \mathrm{m}^{2}\right)$ & $26.2(0.5)$ & $27.0(0.6)$ & & $26.0(0.7)$ & $26.2(0.7)$ \\
Body fat $(\%)$ & $24.7(0.8)$ & $26.0(1.1)$ & & $24.3(1.0)$ & $24.9(0.9)$ \\
\hline
\end{tabular}

Values are mean (SEM).

Poor prognosis group-There were 26 patients with a poor prognosis and their matched controls. Of these, 14 pairs had had an anterior infarct and 12 pairs an inferior infarct.

Fourteen pairs from the good prognosis group and three pairs from the poor prognosis group were taking $\beta$ blockers. Further descriptive characteristics of these groups relevant to exercise rehabilitation are given in table 1 .

STUDY DESIGN AND PROCEDURES

Following a submaximal treadmill test (Modified Bruce, Sheffield protocol, stage III) three weeks after their myocardial infarction, patients were classified as having either a good or a poor prognosis on the basis of their initial responses to early exercise testing (fig 1). The criteria used to determine prognosis included:

- Degree of ST segment depression $(>2 \mathrm{~mm}$ for classification into the poor prognosis group) ${ }^{8}$

- Heart rate response to exercise uncontrolled by medication ( $>130$ beats/min for classification into the poor prognosis group $)^{9} 10$

- Number and classification of ventricular premature beats (rated 3 to 5 on the Lown classification $)^{11} 12$

- Exercise time (considerably less than nine minutes for classification into the poor prognosis group $)^{9} 10$

- Symptoms of chest discomfort and/or dyspnoea (of sufficient intensity to require stopping the test, resulting in classification into the poor prognosis group). ${ }^{9}$

A minimum of at least three negative responses was necessary for final classification into the poor prognosis group. Following an uncomplicated response to early exercise testing and subsequent random allocation to a treatment group, the 36 patients who formed the good prognosis group immediately began aerobic training three times a week for 12 months. The 26 patients who recorded a poor response to early stress testing (the poor prognosis group) began aerobic training eight weeks after their myocardial infarct, three times a

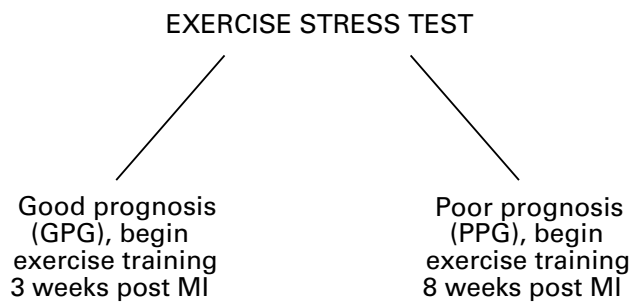

Figure 1 Exercise stress test three weeks after myocardial infarction. week for 12 months (fig 1). All patients within the treatment populations were monitored for the first 12 sessions of exercise using ECG telemetry (lead MCL 5) and, when appropriate, at other times during their training programme (for example, with deterioration of symptoms). The control population for each respective group received no formal exercise training throughout the same 12 month period.

Patients within each group were matched on the basis of the site and severity of their infarcts (cardiac enzymes/ECG changes), age, sex, Peel index score (morbidity rating), and whether they were taking $\beta$ blockers. Maximum testing to end points limited by signs or symptoms, or by volitional exhaustion, was subsequently applied to the whole research population at four, eight, and 12 months.

CARDIORESPIRATORY MEASUREMENTS

During the initial and subsequent tests, submaximal and peak cardiorespiratory responses to exercise were measured using respiratory gas analysis (Sensormedics MMC Horizon metabolic cart, Electro Medical Equipment, Brighton, UK) and 12 lead ECG analysis (Marquette Case II system, Marquette Hellige UK, Kettering Parkway, UK). Blood pressure was measured throughout each test, both manually using a standard sphygmomanometer/stethoscope, and automatically using a Puritan Bennett infrasonde blood pressure monitor (Puritan Bennett, Indianapolis, USA). The original Borg scale for perceived exertion was used to provide a subjective evaluation of exercise intensity during testing and subsequent exercise training. ${ }^{13}$ As an integral part of the research design, a validation study was conducted comparing the Sensormedics metabolic cart with an established "open circuit" method of measuring ventilatory response to exercise. Paired comparisons revealed correlation coefficients between these methods of $r=0.88, \mathrm{p}<0.001\left(\dot{\mathrm{V}}_{2}, 1 / \mathrm{min}\right)$ and $r=0.81, \mathrm{p}<0.001\left(\dot{\mathrm{V}}_{\mathrm{CO}_{2}}, 1 / \mathrm{min}\right)$.

PSYCHOLOGICAL WELLBEING/QUALITY OF LIFE MEASUREMENTS

Before the initial submaximal (three weeks) and maximal assessments (four, eight, and 12 months), a psychological/quality of life test battery was administered to all patients. This included the following:

The Toronto attitude scale-A short 40 item questionnaire adapted from the multiphasic personality inventory, used to record and detect depression. ${ }^{14}{ }^{15}$

The profile of mood states-A 65 item mood adjective checklist, used to record and detect tension/anxiety, dejection/depression, anger/ hostility, vigour/activity, fatigue/inertia, and confusion/bewilderment. ${ }^{16}$

Quality of life-A short 10 item visual analogue scale was used for subjective assessment of quality of life and included the following elements: feeling of wellbeing, mood, level of activity, pain, nausea, appetite, ability to perform housework/job, social activities, level of anxiety, and treatment effectiveness. 
Table 2 Selected cardiorespiratory indices of fitness: exercisers v controls, 4-12 months (good prognosis group)

\begin{tabular}{|c|c|c|c|c|c|c|c|c|c|}
\hline & \multicolumn{3}{|l|}{4 Months } & \multicolumn{3}{|l|}{8 Months } & \multicolumn{3}{|l|}{12 Months } \\
\hline & Exercisers & Controls & $p$ & Exercisers & Controls & $p$ & Exercisers & Controls & $p$ \\
\hline Peak RPP (beats/min/mm Hg) & $269.5(9.5)$ & $214.9(10.2)$ & $<0.001$ & $296.5(10.3)$ & $220.4(11.3)$ & $<0.001$ & $316.3(10.7)$ & $206.3(8.7)$ & $<0.001$ \\
\hline Peak $\dot{\mathrm{V}}_{2}(\mathrm{ml} / \mathrm{kg} / \mathrm{min})$ & $27.3(0.8)$ & $19.6(0.7)$ & $<0.001$ & $29.9(0.8)$ & $20.2(0.6)$ & $<0.001$ & $31.5(0.9)$ & $19.7(0.5)$ & $<0.001$ \\
\hline Exercise time (min) & $15.1(0.2)$ & $11.6(0.3)$ & $<0.001$ & $16.2(0.3)$ & $11.7(0.3)$ & $<0.001$ & $17.3(0.3)$ & $11.6(0.3)$ & $<0.001$ \\
\hline
\end{tabular}

Values are mean (SEM)

$\mathrm{RPP}$, rate-pressure product; $\dot{\mathrm{V}}_{2}$, oxygen consumption.

Table 3 Selected cardiorespiratory indices of fitness: exercisers $v$ controls (poor prognosis group)

\begin{tabular}{|c|c|c|c|c|c|c|c|c|c|}
\hline & \multicolumn{3}{|l|}{4 Months } & \multicolumn{3}{|l|}{8 Months } & \multicolumn{3}{|l|}{12 Months } \\
\hline & Exercisers & Controls & $p$ & Exercisers & Controls & $p$ & Exercisers & Controls & $p$ \\
\hline Peak RPP (beats/min/mm Hg) & $265.6(12.7)$ & $201.3(9.7)$ & $<0.001$ & $271.6(12.1)$ & $206.5(12.1)$ & $<0.001$ & $291.6(11.7)$ & $202.4(11.3)$ & $<0.001$ \\
\hline Peak $\dot{\mathrm{V}}_{2}(\mathrm{ml} / \mathrm{kg} / \mathrm{min})$ & $21.6(0.7)$ & $14.7(0.7)$ & $<0.001$ & $24.5(1.0)$ & $15.9(0.8)$ & $<0.001$ & $25.5(0.9)$ & $14.9(0.8)$ & $<0.001$ \\
\hline Exercise time (min) & $12.5(0.4)$ & $8.1(0.5)$ & $<0.001$ & $13.9(0.3)$ & $8.4(0.5)$ & $<0.001$ & $14.8(0.4)$ & $7.9(0.6)$ & $<0.001$ \\
\hline
\end{tabular}

Values are mean (SEM).

$\mathrm{RPP}$, rate-pressure product; $\dot{\mathrm{VO}}_{2}$, oxygen consumption.

Vocational status/lifestyle change (five year follow up)-Selected aspects reflecting changes in vocational status and lifestyle were measured five years after completing the initial 12 month study. The instrument used for this assessment was a self administered questionnaire designed in accordance with the principles listed in the symposium on methodology for this investigative procedure. ${ }^{17}$ Areas of focus included: employment status (current and past), return to work, changes in occupation, hours worked, time lost from work owing to cardiovascular illness, hospital and family practice visits related to cardiovascular illness, patients still under cardiologists, drugs used to treat cardiovascular conditions, the presence and severity of angina and rates of reinfarction.

EXERCISE TRAINING

Patients in both good and poor prognosis treatment groups received regular aerobic and local muscular endurance training three times a week for a 12 month period. This consisted of warm up and cool down exercises, sit ups, wall bar/bench step ups, cycle ergometry, and a major component centred on the training of aerobic capacity, using walking and jogging.

Each patient's training programme was individually designed and based on the results of regular exercise tests and trial exercise prescriptions. Individual training intensities varied between approximately $50-65 \%$ of measured peak oxygen uptake $\left(\mathrm{V}_{2}\right)$ in the poor prognosis patients and $65-80 \%$ of peak $\dot{\mathrm{V}}_{2}$ in those with a good prognosis. Training for both groups generally began at the lower end of the training regimens, where patients would walk up to a mile at a pace commensurate with their predetermined target heart rates. By the end of

Table 4 Correlation coefficients: peak oxygen uptake v cardiac recovery index, 4-12 months

\begin{tabular}{llll}
\hline & $\begin{array}{l}\text { Test 2 } \\
\text { (4 months after MI) }\end{array}$ & $\begin{array}{l}\text { Test 3 } \\
\text { (8 months after MI) }\end{array}$ & $\begin{array}{l}\text { Test 4 } \\
(12 \text { months after MI) }\end{array}$ \\
\hline $\begin{array}{l}\text { Good prognosis } \\
\text { group exercisers }\end{array}$ & $r=0.56(\mathrm{p}<0.01)$ & $r=0.60(\mathrm{p}<0.001)$ & $r=0.64(\mathrm{p}<0.001)$ \\
$\begin{array}{c}\text { Poor prognosis } \\
\text { group exercisers }\end{array}$ & $r=0.56(\mathrm{p}<0.01)$ & $r=0.60(\mathrm{p}<0.001)$ & $r=0.68(\mathrm{p}<0.001)$ \\
\hline
\end{tabular}

Cardiac recovery index $=$ peak heart rate $($ beats $/ \mathrm{min})-2 \mathrm{~min}$ recovery heart rate $($ beats $/ \mathrm{min})$. training, patients in both groups were often covering distances up to-and in some instances greater than-three miles. Cardiovascular responses to exercise were monitored on a session by session basis and included heart rate, blood pressure (before and after exercise), together with any symptoms experienced by patients during training. In addition, each patient rated their "perceived exertion" in response to every training session using the Borg scale. ${ }^{13}$ Initial training in both groups began with interval work, quickly progressing to continuous aerobic training. ${ }^{18}$

STATISTICAL ANALYSES

Standard parametric statistical techniques were used throughout. The mean and standard error of the mean (SEM) were calculated and used to describe and summarise the data. The standard deviation (SD) was used when appropriate to illustrate the dispersal of scores around the mean. The Student's $t$ test was employed when testing the significance of the difference between two means using the appropriate test for matched or independent means. Analysis of variance was also used where applicable. Differences and relations were considered significant at the 5\% level. Relations between two or more variables were evaluated using the Pearson product moment correlation coefficient. Correlation and regression methods were used to identify interrelations between variables and to measure average improvements over time. The $\chi^{2}$ test of association was used to analyse data from the sample population (five year follow up questionnaire), testing the null hypothesis of "no relation" between two characteristics (for example, time taken to return to work and being an exercise or control patient).

\section{Results}

Differences in cardiorespiratory, psychological, and quality of life scores were compared between good and poor prognosis patients and their matched controls over 12 months. At the five year follow up we considered selected differences in vocational status and lifestyle 
Table 5 Selected indices of psychological wellbeing/quality of life: exercisers v controls, 3 weeks to 12 months (good prognosis group)

\begin{tabular}{|c|c|c|c|c|c|c|c|c|c|c|c|c|}
\hline & \multicolumn{3}{|l|}{3 Weeks } & \multicolumn{3}{|l|}{4 Months } & \multicolumn{3}{|l|}{8 Months } & \multicolumn{3}{|l|}{12 Months } \\
\hline & Exercisers & Controls & $p$ & Exercisers & Controls & $p$ & Exercisers & Controls & $p$ & Exercisers & Controls & $p$ \\
\hline TAS depression "D" score & $10.2(0.6)$ & $8.8(0.5)$ & NS & $8.7(0.7)$ & $8.6(0.6)$ & NS & $7.1(0.6)$ & $7.9(0.6)$ & NS & $5.9(0.7)$ & $8.3(0.8)$ & $<0.05$ \\
\hline $\begin{array}{l}\text { POMS }(1+4 \text { only) } \\
1 . \text { Tension/anxiety } \\
4 \text {. Vigour/activity }\end{array}$ & $\begin{array}{l}43.6(1.5) \\
56.4(1.6)\end{array}$ & $\begin{array}{l}44.3(1.6) \\
55.6(1.6)\end{array}$ & $\begin{array}{l}\text { NS } \\
\text { NS }\end{array}$ & $\begin{array}{l}37.9(1.3) \\
64.7(1.5)\end{array}$ & $\begin{array}{l}40.6(1.5) \\
60.2(1.4)\end{array}$ & $\begin{array}{l}\text { NS } \\
<0.05\end{array}$ & $\begin{array}{l}36.0(0.8) \\
67.2(1.4)\end{array}$ & $\begin{array}{l}37.3(1.2) \\
60.1(1.6)\end{array}$ & $\begin{array}{l}\text { NS } \\
<0.01\end{array}$ & $\begin{array}{l}35.4(1.0) \\
66.0(1.6)\end{array}$ & $\begin{array}{l}39.5(1.4) \\
61.6(1.5)\end{array}$ & $\begin{array}{l}<0.05 \\
<0.05\end{array}$ \\
\hline Quality of life score & $45.1(2.7)$ & $46.8(2.8)$ & NS & $82.5(1.8)$ & $65.0(2.1)$ & $<0.001$ & $84.5(1.4)$ & $63.5(2.2)$ & $<0.001$ & $85.9(1.5)$ & $66.7(2.1)$ & $<0.001$ \\
\hline
\end{tabular}

Values are mean (SEM)

POMS, profile of mood states; TAS, Toronto attitude scale.

Table 6 Selected indices of psychological wellbeing/quality of life: exercisers $v$ controls, 3 weeks to 12 months (poor prognosis group)

\begin{tabular}{|c|c|c|c|c|c|c|c|c|c|c|c|c|}
\hline & \multicolumn{3}{|l|}{3 Weeks } & \multicolumn{3}{|l|}{4 Months } & \multicolumn{3}{|l|}{8 Months } & \multicolumn{3}{|l|}{12 Months } \\
\hline & Exercisers & Controls & $p$ & Exercisers & Controls & $p$ & Exercisers & Controls & $p$ & Exercisers & Controls & $p$ \\
\hline TAS depression "D" score & $9.4(0.8)$ & $8.9(0.6)$ & NS & $8.0(0.6)$ & $8.7(0.9)$ & NS & $7.2(0.6)$ & $9.2(0.9)$ & NS & $6.6(0.6)$ & $9.9(0.7)$ & $<0.001$ \\
\hline $\begin{array}{l}\text { POMS ( } 1+4 \text { only) } \\
1 \text {. Tension/anxiety } \\
4 \text {. Vigour/activity }\end{array}$ & $\begin{array}{l}44.1(1.5) \\
53.5(1.5)\end{array}$ & $\begin{array}{l}43.5(1.7) \\
51.0(1.7)\end{array}$ & $\begin{array}{l}\text { NS } \\
\text { NS }\end{array}$ & $\begin{array}{l}42.3(1.4) \\
60.5(1.6)\end{array}$ & $\begin{array}{l}43.0(1.9) \\
57.7(1.5)\end{array}$ & $\begin{array}{l}\text { NS } \\
\text { NS }\end{array}$ & $\begin{array}{l}37.9(1.2) \\
62.1(1.3)\end{array}$ & $\begin{array}{l}39.8(1.6) \\
57.5(1.4)\end{array}$ & $\begin{array}{l}\text { NS } \\
<0.05\end{array}$ & $\begin{array}{l}37.4(1.3) \\
64.0(1.4)\end{array}$ & $\begin{array}{l}42.0(1.7) \\
57.3(1.5)\end{array}$ & $\begin{array}{l}<0.05 \\
<0.01\end{array}$ \\
\hline Quality of life score & $38.4(3.7)$ & $37.5(3.0)$ & NS & $76.3(2.2)$ & $57.7(2.5)$ & $<0.001$ & $78.9(2.1)$ & $58.0(2.5)$ & $<0.001$ & $80.8(1.2)$ & $59.4(2.2)$ & $<0.001$ \\
\hline
\end{tabular}

Values are mean (SEM).

POMS, profile of mood states; TAS, Toronto attitude scale.

changes when comparing the total exercising populations (good and poor prognosis combined) with their matched controls.

CARDIORESPIRATORY FITNESS

Immediately after the initial exercise stress test, three weeks postinfarction, there were no significant differences between the good and poor prognosis groups and their matched controls. However, from the fourth month to the end of the first year there were statistically significant differences in cardiorespiratory fitness within both the good and poor prognosis exercise groups compared with their matched controls. Thus the treatment population had greater rate-pressure product $(\mathrm{p}<0.001)$ and oxygen uptake $(\mathrm{p}<0.001)$ at peak exertion, reflecting an improved exercise time $(\mathrm{p}<0.001)$ compared with their matched controls (tables 2 and 3 ). The most strongly positive correlations were between the peak oxygen uptake $\left(\dot{\mathrm{V}}_{2}, \mathrm{ml} / \mathrm{kg} / \mathrm{min}\right)$ and the cardiac recovery index (CRI, beats/min) in the treatment

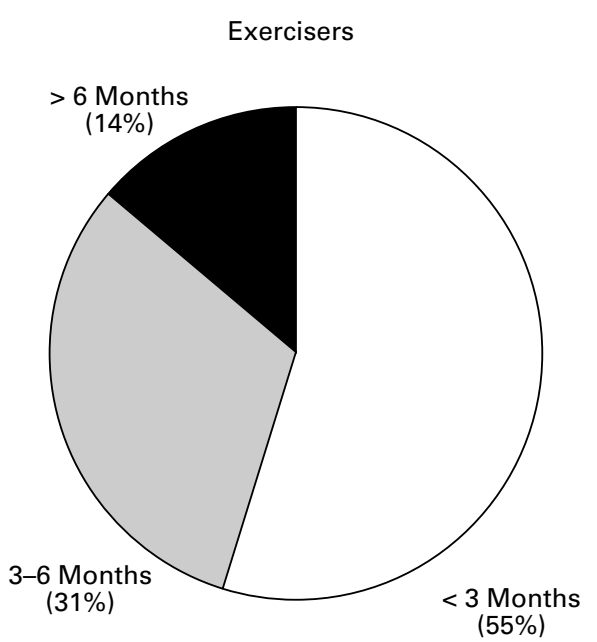

population..$^{19}$ Following 12 months of training, coefficients of correlation were $r=0.64$ $(\mathrm{p}<0.001)$ in the good prognosis exercisers, and $r=0.68(\mathrm{p}<0.001)$ in the poor prognosis exercisers. This relation became more pronounced as cardiorespiratory fitness improved from four to 12 months (table 4). From four to 12 months, both exercising populations recorded significantly greater levels of ST segment depression at peak exertion compared with their matched controls (good prognosis exercisers: -0.7 to $-0.9 \mathrm{~mm}$, $v$ good prognosis controls, -0.4 to $-0.3 \mathrm{~mm}$; $<0.05-<0.001$; poor prognosis exercisers, -1.1 to $-1.4 \mathrm{~mm}$, $v$ poor prognosis controls, -0.3 to $-0.4 \mathrm{~mm}$; $\mathrm{p}<0.01-<0.001)$. During this period, there were three syncopal episodes relating to exercise, two of these occurring during the recovery phase following physical activity. All of them resolved spontaneously without cardiovascular complications or injury. There were no cardiac arrests during the 12 month exercise training period.

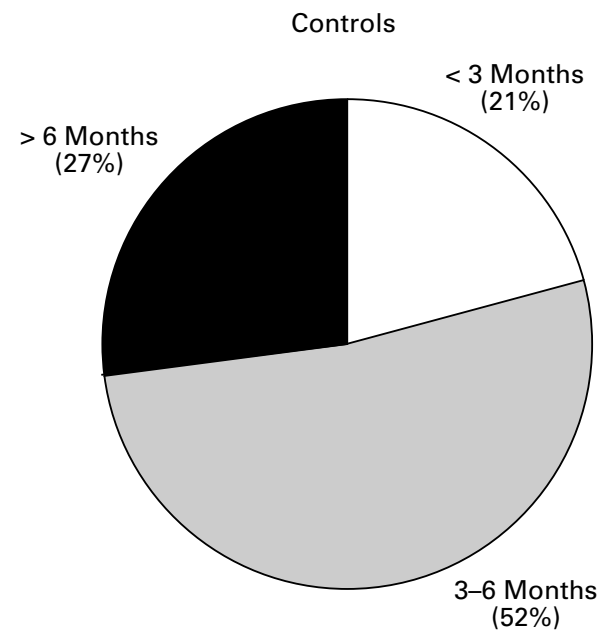

Figure 2 Percentage of exercisers $v$ controls returning to work less than three months, three to six months, more than six months after myocardial infarction. Total postmyocardial infarction population $p<0.05$. 
Exercisers

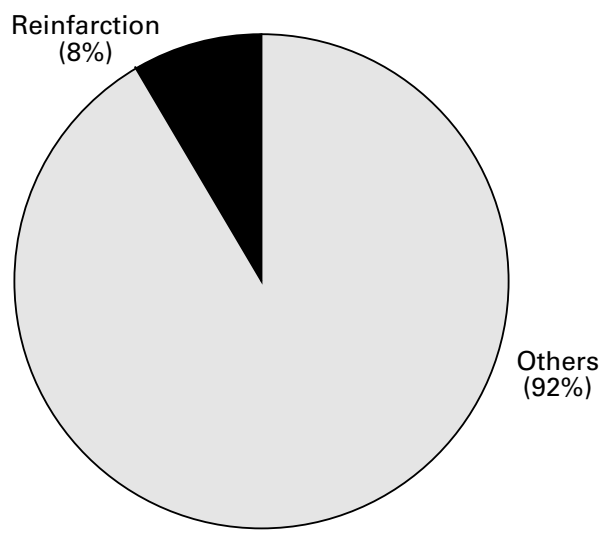

Controls

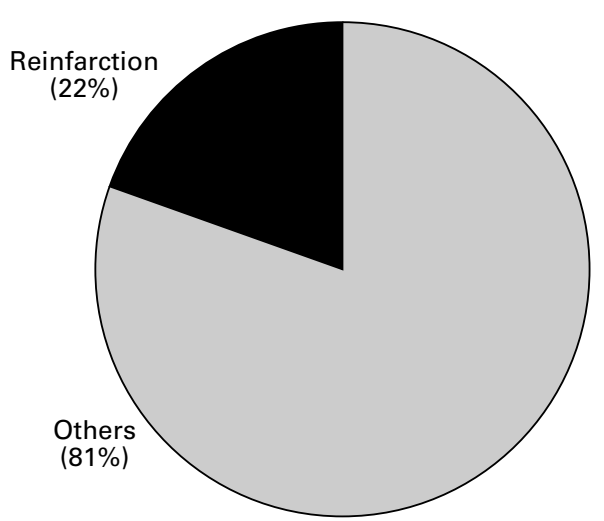

Figure 3 Percentage of exercisers $v$ controls suffering a reinfarction (five year follow up). Total postmyocardial infarction population $p<0.05$.

PSYCHOLOGICAL WELLBEING/QUALITY OF LIFE Significant improvements in selected measures of psychological wellbeing were recorded by both treatment populations compared with their matched controls. Differences in many of these variables did not become statistically significant until 12 months of exercise training had been completed. This was particularly evident when comparing the Toronto attitude scale depression scores in both the good and the poor prognosis exercisers with their matched controls (tables 5 and 6). Results from many of the other psychological variables measured followed a similar pattern, as illustrated through the tension/anxiety scores (profile of mood state ("POMS") test; see tables 5 and 6). An exception was the earlier improvement in vigour/ activity scores (POMS, item 4) within both treatment groups and, in particular, in the good prognosis exercisers ( $p<0.05$; table 5$)$. Both the treatment and control populations increased their quality of life scores over 12 months. These improvements were significantly greater in the patients receiving regular exercise rehabilitation ( $\mathrm{p}<0.001$; tables 5 and 6 ).

VOCATIONAL STATUS/LIFESTYLE CHANGE (5 YEAR FOLLOW UP)

In all, 119 completed questionnaires were received from this research population ( $\mathrm{n}=124)$, representing a $95.6 \%$ compliance rate for this investigative procedure. A significantly larger percentage of the total treatment population was in full time employment compared with their matched controls five years after completing the study (68\% v 37\%) $(\mathrm{p}<0.01)$. The regular exercisers also returned to work earlier than their controls following their myocardial infarction ( $\mathrm{p}<0.05$; fig 2). In contrast, $39 \%$ of the controls took up easier/lighter work over the five year follow up period, compared with only $14 \%$ of the treatment population $(\mathrm{p}<0.05)$. Similarly, $58 \%$ of the controls lost time from work because of their ischaemic heart disease (excluding outpatient visits), compared with $26 \%$ of the treatment population $(\mathrm{p}<0.01)$.

There were five recorded deaths directly attributable to reinfarction over the five year follow up period; two in the treatment popula- tion and three in the controls. The exercising groups suffered significantly fewer non-fatal reinfarctions (8\%) compared with their matched controls $(22 \%)$ over the five year follow up period ( $\mathrm{p}<0.05$; fig 3 ). In addition, the exercising group visited their general practitioners less often on an annual basis $(p<0.01)$ and fewer of them were still under a consultant physician five years after their infarction $(p<0.05)$. Although not statistically significant, there was also a clear trend for the intervention group to be taking fewer drugs and to have fewer hospital readmissions directly associated with cardiovascular problems over that same five year period. Most significantly, the intervention group reported less angina than their controls ( $p<0.001$; fig 4$)$.

\section{Discussion}

There have been few randomised controlled trials of exercise in the rehabilitation of postmyocardial infarction populations in the United Kingdom. The early investigations gave the impetus for the wide acceptance of this type of management. ${ }^{120}$ However, subsequent research was often criticised on the basis of poor patient selection criteria, lack of randomisation, and inadequate controls. ${ }^{5}$ Other studies within the United Kingdom lacked precision in their definition and application of exercise, often producing inconclusive results. ${ }^{4}$ An exception to this was the work of Bethell and Mullee, ${ }^{2}$ who showed that on completion of a controlled trial of community based coronary rehabilitation, there was a reduction in angina among the active participants. It was against this background that our study was undertaken, because we saw that there was a need to quantify more accurately the effects of prolonged exercise training after myocardial infarction.

The higher level of cardiorespiratory fitness in the treatment population in our study supports the well documented benefit of prolonged aerobic training. ${ }^{18}$ Although the increase in peak $\dot{\mathrm{V}}_{2}$ from four to 12 months at first appears modest in both groups of exercisers, this does represent a $13-15 \%$ improvement in those groups over an eight month period. 
Exercisers

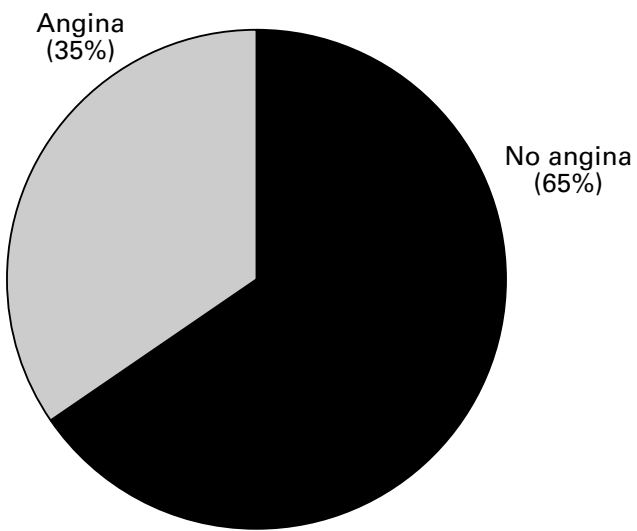

Controls

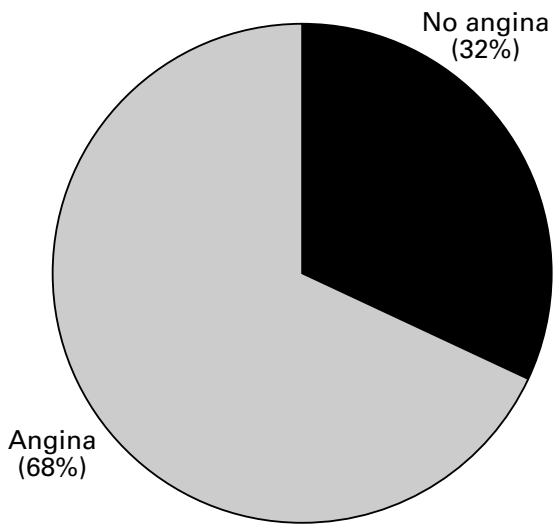

Figure 4 Percentage of exercisers $v$ controls suffering from angina (five year follow up). Total postmyocardial infarction population $p<0.001$.

This is encouraging, especially when compared with little to no improvement in their matched controls. It might be expected that the patients with fewer complications (the good prognosis exercisers) would show a greater improvement in fitness because of the higher intensity of their training. ${ }^{21}$ However, the improvement in cardiorespiratory fitness in the poor prognosis patients with regular exercise is particularly encouraging, illustrating the effectiveness of low/moderate intensity aerobic training in higher risk groups. Recent research by Coats and associates ${ }^{22}$ in the United Kingdom further supports the potential for exercise even in high risk groups - these investigators showed a definite benefit of exercise training in patients with New York Heart Association class II and III heart failure. The positive correlation between peak oxygen consumption and cardiac recovery index ${ }^{19}$ may be important in the practical cardiac rehabilitation setting. Thus, even though it may not be possible in an individual programme to measure oxygen uptake directly, an increase in cardiac recovery index accompanied by other markers (for example a fall in the rate of perceived exertion for the same work intensity) will suggest an improvement in fitness. Observing such changes may help to modify a patient's exercise prescription to maximise training benefit. It is also important to emphasise that despite significantly higher levels of ST segment depression at peak exertion, particularly in the poor prognosis treatment group, regular exercise training intensities were set at considerably lower levels, with correspondingly less ST segment depression $(<1.0 \mathrm{~mm})$. There may be several other important clinical implications associated with these findings, as yet unappreciated but likely to need further investigation. Longer periods of clinical surveillance with higher risk groups following myocardial infarction may therefore be clinically valuable.

Improvements in psychological wellbeing, as reflected by reductions in depression score (TAS) and tension/anxiety score (POMS, item 2), have been reported before during cardiac rehabilitation. ${ }^{23}$ Postmyocardial infarction patients with high depression scores have shown significant improvement following a long term jogging programme. ${ }^{24}$ While accepting such changes, Langosch ${ }^{25}$ emphasises that depression scores often remain relatively high on completion of an exercise regimen. In our treatment population, however, depression scores were approaching the levels found in normal individuals after 12 months of rehabilitation. This was particularly evident in the regularly exercising good prognosis group and may encourage the cardiac rehabilitation specialist to re-evaluate shorter programmes and their expectations. Morgan and co-workers observed that exercise reduced depression scores to a greater extent in patients who were depressed before taking part in an exercise programme. ${ }^{26}$ While we accept that this might influence the magnitude of change, neither of our control populations showed significant reductions in depression scores over the 12 month study period. Early improvement in the vigour/activity scores (POMS, item 4), particularly in the good prognosis exercisers, supports the view that patients involved in regular exercise training feel more physically able to cope with recovery after myocardial infarction. ${ }^{15}$

In our study, quality of life improved in the treatment and the control groups, but the greater improvement in the former from four to 12 months complements their improved levels of fitness, and probably reflects the attention they received through regular rehabilitation. Interestingly, the improvement in the quality of life scores occurred in both the physical and the psychosocial elements, and was more marked in the regular exercisers. Few randomised controlled studies have addressed the issue of vocational change and its effects in postmyocardial infarction patients undertaking regular exercise rehabilitation. ${ }^{27}$ The findings in our study are similar to those reported by Levin and co-workers in Sweden, ${ }^{28}$ in that a significantly greater percentage of the total exercising population $(68 \%)$ were still in full time employment after five years, compared with $37 \%$ of the control population. This population included a spread of occupations ranging from senior executives to blue collar workers, the latter slightly predominating. Equally encouraging is the earlier return to work in regularly exercising patients compared with their less active counterparts (fig 2). Earlier return to 
work has important economic and financial implications. Patients receiving effective interventions after uncomplicated myocardial infarction have been reported to be capable of generating a $22 \%$ greater earning capacity over the first six months after their cardiac event. ${ }^{29}$ The results of our study emphasise the value of exercise rehabilitation, particularly in the light of other United Kingdom reports that have documented a $35 \%$ reduction in return to work ratios at 18 months after infarction in patients not receiving such treatment. ${ }^{30}$ This finding is supported by our control population, who were more likely to take up lighter or easier work and lost significantly more time from work compared with the regular exercisers.

The lack of significant differences in mortality in the treatment and control populations is not surprising, given the relatively small sample size. Our results are comparable with other reports. ${ }^{31}{ }^{32}$ Significant reductions in mortality have been shown in regularly exercising postmyocardial infarction populations using pooled data from several studies. ${ }^{33} 34$ Our own study did, however, show a significantly lower rate of non-fatal reinfarction and angina in the treatment population overall compared with the control population. Our data are comparable with those of Hedback and Perk, ${ }^{35}$ although differing in that we used a more vigorous exercise component. Returning to active employment should improve the patients own self confidence and positively influence the cost-effectiveness/ benefit of providing cardiac rehabilitation services. The latter needs to be considered carefully, as health care providers are increasingly being required to evaluate their services in terms of health care costs and patient outcomes. ${ }^{36}{ }^{37}$ Our intervention group had fewer visits to their general practitioners and fewer of them were still under care of a hospital consultant for cardiovascular illness at the end of the observation period. This implies a substantial improvement in the cost-benefit ratio. In addition, the fact that patients who receive such rehabilitation are less likely to be readmitted to hospital with cardiovascular problems and are more likely to have their drugs reduced has further implications for cost saving.

CONCLUSIONS

The results of our study clearly identify benefits for patients undertaking comprehensive exercise rehabilitation. Stratifying postmyocardial infarction populations through the use of early exercise testing may help triage patients towards the safest and most effective forms of treatment for their ischaemic heart disease. Serial exercise testing over the following 12 months can also provide valuable clinical information and positively influence case management. ${ }^{38}$ The cost-effectiveness benefit linked with such a provision appears very favourable, but more studies are needed to examine these aspects. Our findings support the recommendations of two British Cardiac Society working party reports on cardiac rehabilitation. ${ }^{67}$ They substantiate a national review of cardiac rehabilitation and its guidelines on standards and local recommendations in the most recent report on cardiology in district general hospitals. ${ }^{39} 40$ All these reports encourage health authorities to provide a multidisciplinary cardiac rehabilitation service. The length of time over which such a service should be provided needs to be reviewed in the light of our present findings, which were based on a 12 month exercise intervention programme. With an increasing focus on evidence based medicine, an extended programme lasting up to 12 months may have advantages. Following this study a two year scheme is currently in use within the district general hospital setting. It is increasingly concentrating on "maintenance rehabilitation" (phase IV), using a combination of home and centre based interventions. In addition, there is a growing community involvement in the work of the centre, with an added focus on the prevention of ischaemic heart disease.

1 Carson P, Phillips R, Lloyd M, et al. Exercise after myocardial infarction: a controlled trial. $\mathcal{F} R$ Coll Physicians 1982;16:147-51

2 Bethell $\mathrm{H}$, Mullee M. A controlled trial of community based coronary rehabilitation. Br Heart f 1990;64:370-5.

3 Dugmore LD. Exercise and heart disease. In: The community prevention of coronary heat disease. London: HMSO, 1990:43-58.

4 Mayou R, MacMahon D, Sleight P, et al. Early rehabilitation after myocardial infarction. Lancet 1982:ii:1399-401.

5 Lipkin D. Is cardiac rehabilitation necessary? Br Heart $\mathcal{f}$ 1991;65:237-8.

6 Horgan J, Bethell H, Carson P, et al. The British Cardiac Society working party report on cardiac rehabilitation. $\mathrm{Br}$ Society working party repor
Heart $\mathcal{f} 1992 ; 67: 412-18$

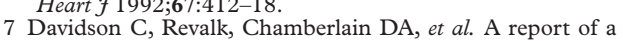
working group of the British Cardiac Society: cardiac rehabilitation services in the United Kingdom 1992. Br Heart 7 1995;73:201-2.

8 DeBusk R, Blonqvist C, Kouchoukos N. Identification and treatment of low risk patients after acute myocardial infarction and coronary artery bypass graft surgery. $N$ Engl f Med 1986;314:161-6.

9 Theroux P, Waters D, Halphen C. Prognostic value of exercise testing soon after myocardial infarction. $N$ Engl f Med 1979;301:341-5.

10 Bigger J, Dresdale R. Ventricular arrhythmias in ischaemic heart disease: mechanism, prevalence, significance, and management. Prog Cardiovasc Dis 1977;19:255-300.

11 DeBusk R, Haskell W. Symptom limited versus heart rate limited exercise testing soon after myocardial infarction. Circulation $1980 ; 61: 738-43$.
Cimited exercise testing soon

12 Ruberman W. Ventricular premature beats and mortality after myocardial infarction. N Engl F Med 1977;279:750-7. 13 Borg GA. Physical performance and perceived exertion. Lund: Gleerup, 1962:1-63.

14 Hathaway S, McKinley J. A multiphasic personality schedule after myocardial infarction. Eur Heart f 1940;8: 234-42.

15 Kavanagh T, Shephard R, Tuck J. Depression after myocardial infarction. F Can Med Assoc 1975;113:23-7.

16 McNair D, Lorr M, Droppleman XX. Profile of mood states. San Diego, California: Education and Industrial Testing Service, 1971:1-27.

17 Staples D. Questionnaires (symposium on methodology). Clin Rehabil 1991;5:259-64.

18 Astrande P, Rodahl K. Textbook of work physiology. New York: McGraw Hill, 1986:423-7, 453.

19 Burke E, Humphreys J. Fit to exercise. London: Pelham Books, 1982:126-7.

20 Nixon P. Rehabilitation of the coronary patient. Physiotherapy 1972;58:10.

21 Ehsani A, Heath G, Hagberg J, et al. Effects of 12 months of intensive exercise training on ischaemic ST segment depression in patients with coronary heart disease. Circulation $1981 ; 64: 1116-24$

22 Coats AJS, Adamopoulos S, Meyer TE, et al. The effects of physical training in chronic heart failure. Lancet 1990;335: 63-6.

23 Kavanagh T. Distance running and cardiac rehabilitation: physiologic and psychosocial considerations. Clin Sports Med 1984;3:513-26.

24 Kavanagh T, Shephard R, Tuck J, et al. Depression following myocardial infarction: the effects of distance running. Ann NY Acad Sci 1977;301:1029-38.

25 Langosch W. Psychological effects of training in coronary patients: a critical review of the literature. Eur Heart $\mathcal{f}$ 1988;9(suppl M):37-42.

26 Morgan W, Robert J, Brand F. Psychological effects of chronic Morgan W, Robert J, Brand F. Psychological effects of chr
physical activity. Med Sci Sports Exerc 1970;2:213-17.

27 Danchin N. Work capacity after myocardial revascularization: factors related to work resumption. Eur Heart $\mathcal{F} 1988 ; 9$ (suppl L):44-8. 
28 Levin L, Perk J, Hedback B. Cardiac rehabilitation: a cost analysis. F Intern Med 1991;230:427-34.

29 Dennis C, Houston Miller N, Schwartz R. Early return to work after myocardial infarction and/or revascularization. Eur Heart f 1988;9(suppl L):130-31.

30 Watson P, Mayberry J, Calcraft B, et al. Employment after myocardial infarction amongst previously healthy men. $\mathcal{F} R$ Soc Med 1986;79:329-30.

31 Lamm G, Denolin H, Dorossiev D, et al. Rehabilitation and secondary prevention of patients after acute myocardial infarction: WHO collaborative study. Adv Cardiol 1982;31: 107-11.

32 Rechnitzer P, Cunningham D, Andrew G, et al. Relation of exercise to the recurrence rate of myocardial infarction in men: Ontario exercise-heart collaborative study $A m 7$ Cardiol 1983;51:65-9.

33 Oldridge N, Guyatt G, Fischer M, et al. Cardiac rehabilitation after myocardial infarction: combined experience of randomized clinical trials. $\mathscr{f} A M A$ 1988;260:945-50.
34 O'Connor G, Buring J, Yusuf S, et al. An overview of randomized trials of rehabilitation with exercise after myocarial infarctions. Circulation 1989;80:234-44.

35 Hedback B, Perk J. Five year results of a comprehensive rehabilitation program after myocardial infarction. Eur Heart f 1987;8:234-42.

36 Oldridge N. Health-related quality of life: assessment and outcome in cardiac rehabilitation. In: Proceedings of the Canadian Association of Cardiac Rehabilitation, Edmonton, Canada, 1994.

37 Guyatt G, Feeny D, Patrick D. Measuring health-related quality of life. Ann Intern Med 1993;118:622-9.

38 Franklin BA, Gordon S, Timmis GC. Exercise in modern medicine. Baltimore: Williams and Wilkins, 1989:1-19.

39 Thompson DR, Bowman GS, Kitson AL, et al. Cardiac rehabilitation in the United Kingdom; guidelines and audit standards. Heart 1996;75:89-93.

40 Cardiology in the district hospital. A report of a working group of the British Cardiac Society. Br Heart f 1994;72:303-8. 